\title{
Ethnopoetic Analysis of the Dagbamba Song Riddles
}

\author{
Mohammed Abubakari Rashid \\ Languages Department, E. P. College of Education, Bimbilla, Ghana \\ Email address: \\ rashid4all2u@gmail.com
}

To cite this article:

Mohammed Abubakari Rashid. Ethnopoetic Analysis of the Dagbamba Song Riddles. International Journal of Applied Linguistics and Translation. Vol. 6, No. 3, 2020, pp. 59-67. doi: 10.11648/j.ijalt.20200603.11

Received: April 17, 2020; Accepted: May 19, 2020; Published: June 8, 2020

\begin{abstract}
This paper discusses the song riddle (Tuya duyibu) among the Dagbamba in the Northern Region of Ghana. Data for this study were taken from recordings of interviews as well as native speaker intuition and analyzed within the theoretical framework of Jacobson's Ethnopoetic Theory. The paper shows that the Dagbamba song riddle has the antecedent and a response as its parts. I show in the paper that the Dagbamba song riddles have alliteration and pilling as a repetitive pattern. Again, the paper shows that the dominant ratio of the number of elements (elements pattern) employed in the Dagbamba song riddle performance of both the antecedents and the responses is $2: 2$. It is also shown in the paper that there is no syllabic equivalence in the Dagbamba song riddle, but short and open syllables are most prominently employed in both the song riddle antecedents and responses. Also shown in this paper is the opening formula. The song riddle is peculiar because, apart from it being sang as a song, it is also accompanied with gestures and dance during its enactment. As a relationship, the Dagbamba song riddle cautions the Dagbamba society against divorce didactically. The paper serves as a way of documenting the knowledge of literature and augmenting the existing knowledge of literature among the Dagbamba since modernity is seen as a threat to Dagbamba folklore.
\end{abstract}

Keywords: Riddle, Ethnopoetic, Dagbamba and Antecedent

\section{Introduction}

This study seeks to discuss the song riddling Tuya duyibu among the Dagbamba in the Northern part of Ghana. Dagbani is the language spoken by the Dagbamba. It has three distinct dialects also spoken in the area. These dialects includes the western dialect (Tomosili), spoken in and around the administrative capital of Northern Region of Ghana, Tamale. The Eastern dialect (Nayahili) which is also spoken in Yendi, the traditional capital of Dagbay and its environs, and Nanuni, the Southern dialect, spoken in and around Bimbilla. The land occupied by the Dagbamba is called Dagbay. Dagbani is classified among the Mabia Languages, a component of the Niger-Congo language family and spoken in the Northern part of Ghana [5]. The native speakers know themselves as Dagbana (singular) and Dagbamba (plural). These two forms are also referred to as Dagomba (singular) and Dagombas (plural) respectively by non-native speakers. The language is mutually intelligible with Mampruli, who according to oral tradition, are historical brothers of common ancestry. Dagbani is closely related to Gurene, Dagaare,
Kusaal and Waali among the other Mabia Languages.

Interestingly, the riddles were not consequent from actual riddle sessions but were elicited during interviews from informants. On song riddle among the Dagbamba not much seems to be known. Notably, no observations made on the song riddles among the Dgabamba were found in the existing literature hence the vitality of this study. It will therefore not misleading to say that certain Dagbani oral literature and folklores may be extinct due to the influence of modernity. This study, therefore, would eventually contribute to a better understanding of the Dagbamba song riddle which syndicates the culture and the oral constructions in its performance.

The song riddle among the Dagbamba, unlike other riddles in some cultures Such as the Bagobo riddles reported by Manuel [13], where they riddle during day or where there are no restrictions of the riddle performance, is restricted to certain periods of the night, or prescribed occasions or important periods in social life such as the riddle contest/game performed only during the night when the community folks gather at a place known among the Dagbamba as Salingryu $n i$ to perform stories and riddles. It may be performed on moonlight nights before going to sleep, 
after a successful farming or hunting day or during weddings. Song riddles are commonly performed during the long evenings when there is corn or groundnut shelling to be done apart from listening to the discussion of the adults. Therefore, among the Dagbamba, it is a taboo for people to perform the song riddle and any form of riddles during day, for they may be seen as lazy people and the culture frowns at laziness. The assumption is that, every Dagbana will be busy working during day and so people who will be found performing riddles have either left work or are idle.

Ideally, any child from 4 years up until marriage can observe or participate in a song riddle session, therefore, there are no formal age groups among the Dagbamba of which the performance of the song riddle is done. It is actually in this formal peer group that riddling is established, that is, the unmarried individuals. The older people often listen but do not participate in the song riddle performance. They are restricted to giving sarcastic remarks about the song riddles. Therefore song riddling mostly ceases after marriage to married individuals. Song riddle performance primarily appropriate to the young, is regarded among the Dagbamba as a source of confidence building and entertainment.

The way in which the song riddle is formulated is important. If the opponent (s) do (es) not agree to the formulation of the riddle which might have been misleading or not in accordance with the traditional forms and imagery that thus leads to a possible reason for the failure of the opponent. The contestant (s) could come to disagreement which may sometimes lead to abruption of the riddle session. Sometimes different solutions are allowed by the riddler due to difference in geographical location.

In this study, a riddle antecedent and its corresponding response is taken as a line.

\section{Theoretical Framework}

In providing the analysis, I intend to apply Roman Jacobson's [12] Ethnopoetic Theory. The fundamental principles of ethnopoetic analysis is that, performed oral narratives are organized in terms of lines, and groups of lines (not in terms of sentences and paragraphs). The relations between lines and groups of lines are based on the general principle of poetic organization called equivalence [12]. Equivalence may involve any feature of language. Metrical forms of equivalence such as stress, tonal accent, syllable, initial consonant (alliteration) constitute lines. Lines of whatever length may also be treated as equivalent in terms of the various forms of rhyme, tone group or intonation contour, initial particles, recurrent syntactic pattern, consistency of contrast of grammatical feature, such as tense or aspect. The ethnopoetic relations are reflected in details of capitalization and punctuation. These devices are not simply grammatical, but also rhetorical. An ethnopoetic perspective shows that oral narrations have a considerable degree of structure and identifying such structure helps an individual to recognize the actual presence of evaluation. Hymes [11] concedes to the use of Ethnopoetic analysis in analyzing oral art forms by saying that Ethnopoetics analysis unearths the implicit poetic structure of an oral narrative when it is represented as prose.

\section{Opening Formula of the Dagbamba Song Riddle}

The Dagbamba song riddles are not just haphazardly performed. A call for the performance has to be made and this call requires positive response from the entire members of the riddle contest, if not, there is not going to be adherence to the call. After this call, the phrase or sentence that the performers use to open this riddle performance, in this study, is the opening formula. The Dagbamba song riddle has Ti duyimiya tuya 'let us cook beans' as its opening formula. A volunteer will usually call for either a switch or start of the performance of the song riddle by saying Ti duyimiya tuya! 'Let us cook beans', Ti duyimiya tuya! 'Let us cook beans.' When it is a contest/game between two groups, anybody from one of the competing groups will call for the performance. Similarly, anybody from the other competing group responds to the call by saying To! 'Yes/okay', To! 'Yes/okay'. The group that calls for the performance therefore will start the performance with the first antecedent of the song riddle and the other group responds or provides response to the antecedent. The performance of this type of riddle is either done by a group member, that is, a member of the group that first called for the performance will be performing the antecedent and all the members of the other group will be supplying the right responses to the antecedents. Or, each member of the competing groups will be performing the antecedent and the response concomitantly. It can also be performed simultaneously between two individuals in a riddle session. Winner (s) is/are, of course, the individual/group who/which has provided all the required responses of the song riddles.

\section{Song Riddles (Tuya duyibu)}

One of the types of riddles recorded among the Dagbamba is the song riddle. This is performed in the form of action songs and sometimes accompanied with a dance or gestures.

The song riddle is mostly sung either by an individual who proposes the riddle and responds to it himself using the last words of the response as the antecedent which is always preceded by an interrogative. Or an individual who proposes the riddle to be responded by a group of performers. These types of performances are referred to as monochoral and antiphonal performances respectively. Where an individual performs both the antecedents and the responses, it is monochoral and antiphonal performance is where a group of performers performs the antecedents and the other group also performs the responses (Okpewho [17]; Maureen [15]). It could also be performed by an individual from a group of riddle contest who proposes the riddle to be responded by an individual from the opposing group of performers. This, therefore, signifies that one song riddle is a composition of 
several antecedents and responses and each line of the song riddle is related. In some cases, the performance of song riddles may be more than two individuals. The performer unwittingly gets an inkling of the structure of the song riddle. There are most times syllable correspondence in the antecedents and the responses in the Dagbani song riddle. Short syllables are the most prominent and the long syllables are less prominent.

Song riddles have also been reported of the Makua of Tanzania by Harries [10] and Farifare riddles by Nsoh, Fusheini and Ababila [16]. Like those of the Makua, antecedent and response are proposed by the same reciter. Thus, the song riddles are recitals with fixed forms. Unlike the other riddles, the song riddles are performed on a song tone. They are several antecedents and responses composed in a song riddle. Each line is related to each other through an enjambment. Contrary to the observation made by Nsoh, Fusheini and Ababila [16] on the Farifare song riddle where the opening line is a statement, the opening line of the Dagbamba song riddle is always a question. Some of the words in the Dagbamba song riddle are meaningless words in the language but are idiomatically used as referents to some euphemism. The final statement is mostly a proverb relevant to the riddle theme and the society at large. Dagbamba song riddles conform with Finnegan's assertion that song riddles are characterized by their erotic content and allusion, practically referring to sex [8].

All the antecedents and the responses of the Dagbamba song riddles are organized according to a specific patterning. There is also a syntactic relations subtly powerfully present which nobody has a way of referring to it in the speech community. There is also a rhythm to the riddle patterning of the antecedents. The shorter names at the antecedents suits the speaker, unaccountably for him, as a well-ordered shape for a message.

The logical pattern organizes experience into symmetrical, regular relationships, and these relationships are used to segment the riddle into sets with parts. The relationship between the antecedent and the response is grouped in an implicit cultural patterning of the form of action, logic, or rhetoric of experience, such that the form of language and the form of culture are one and the same. It, thus presupposes that the richness of syntax which linguistics finds in every child may be accompanied by the richness of riddle organization. Children listening or taking part in song riddling contest, samples of language are being presented and implicit organization of experience into satisfying patterns is conveyed and may be internalized. These patterns are exploited by the riddler to put the audience in suspense and then carry over and double the pattern. The patterns are normally marked by initial grammatical particles. At certain points in the riddle, some words recur. The repetition of the words may mark off unit in the riddles. The elements repeated give bits of clues about the constituents of the response which gives the pattern a consistent relationship. It also connects the action with turn taking. Turns of riddles may count as units but most of the repeated elements are part of the unfolding of the logic of the event, of sequence of actions. Further niceties of pattern that bears on the relationship between the riddlers are part of the aesthetic effect.

The Dagbamba song riddle was originally performed among females. Probably to have sex groupings due to the culture frowning at opposite sex groupings at the time. A song riddle among the Dagbamba is seen in excerpt 1 below.
Excerpt 1.

A: Bo $m$-be a nolini? 'What is in your mouth?'

A: Bo tuya? 'What beans?'

A: Bo bandi? 'What fetters?'

A: Bo kulo? 'What kulo?'

A: Bo kpam? 'What oil?'

A: Bo diti? 'What ugly?'

A: Bo sangara? 'What problem?'

A: Bo suyuls? 'What patient?'

A: Bo ku n-kpe? 'What can't enter?'

A: Bo yemba? 'What yemba?'

A: Bo payisara? 'What ladies?'

A: Bo dii? 'What really?'

A: Bo lam? 'What taste?'

A: Bo tari? 'What plaster?'

A: Bo bolo? 'What slippery?'

A: Bo wumsi? 'What nurses?'

A: Bo chayila? 'What jingles?'

A: Bo fiiyo? 'What fiiyo?'

A: Bo goy? What crooked?

A: Bo piti? 'What tasteless?'

\author{
R: Tuya 'beans' \\ R: Tuya bandi 'beans fetters' \\ R: Bandi kulo 'fetters kulo (meaningless)' \\ $\mathrm{R}$ : Kulo kpam 'kulo oil' \\ R: Kpam diti 'ugly oil' \\ $\mathrm{R}$ : Diti sangara 'ugly problem' \\ R: Sangara suyulo 'patient's problem' \\ R: Suyulo ku n-kpe 'patient can't enter' \\ $\mathrm{R}$ : Ku n-kpe ycmba 'ycmba (meaningless) can't enter' \\ $\mathrm{R}$ : Yemba payisara 'ycmba ladies' \\ R: Payisara dii 'really ladies' \\ R: Diidii lam 'really taste' \\ R: Lam tari 'taste plaster' \\ R: Tari bolo 'slippery plaster' \\ R: Bolo wumsi 'nurses slippery' \\ Re: Wumsi chayila 'nurses jingles' \\ R: Chayila fiiyo 'jingles fiiyo (meaningless)' \\ R: Fiiyo goy 'fiiyo crooked' \\ R: Goy piti 'tasteless crooked' \\ R: Piti zaa m-bala ka $m$ bi nya sheli. Daadali binchcrili ka so yun nya \\ m-mali goyira. 'Lit: It is the market day's rag that someone gets and \\ brags with it.'
}




\subsection{Repetitive and Element Patterns}

Repetition, a literary term, is employed by the performer of the Dagbamba song riddle; it deals with recurrent use of the same words, phrases or sound patterns a few times for emphasis. It makes the idea in the riddles clearer or emphasizes the significance of the recurrent word or phrase in the entire riddles. It is also sometimes used ironically to lure the listener or performer into a state of expectation and then shocked by unexpected twist.

From the preceding example, one would observe that the performer employed and maintained a repetitive device in the riddling cohort of all the riddle antecedents by repeating the interrogative marker $B$ J 'what' in all the Dagbamba song riddle antecedents. $B \supset$ 'what' is repeated as the first word of all the antecedents of the song riddle to make it anaphoric. The anaphoric interrogative is therefore employed to lay emphasis on the significance of the interrogative and the need to respond to the antecedent in the riddle by the riddlee. There is also an alliteration of the consonant sound $/ b /$ in the first elements (the interrogative marker $B$ J 'what') of all the riddle antecedents. This creates a rhythmic pattern in all the antecedents of the song riddle antecedents. Though the emphasis of the model is on alliteration, there is also assonantal rhyme of the vowel sound $/ \partial /$ in the interrogative BJ 'what'.

Though, the same element is repeated in this riddle antecedent and its response, nonetheless, there is also repeated pattern of at least a consonant sound in the response of the preceding antecedent and in the antecedent and the response of the next riddle antecedent and its response. Thus, a consonant sound found in a preceding response, especially consonant sound in the second elements of the immediate preceding response, is repeated at least twice in the next antecedent/ and response, especially, in the second and first elements of the antecedent and the response respectively of the song riddle. For instance, the consonant sounds $/ t /$ and $/ \mathrm{j} /$ in the first response tuya 'beans', is repeated in the second riddle antecedent and its corresponding second response. Again, the consonant sounds $/ \mathrm{b} /, / \mathrm{n} /$ and $/ \mathrm{d} /$ in the second element of the second response are repeated in the second element of the third antecedent and its response. Therefore, the consonant sounds in kulo that is, $/ \mathrm{k} /$ and $/ 1 /$ are repeated in the second and third elements of the next riddle antecedent and response respectively. This is a constant repetitive phenomenal pattern employed by the riddle performer throughout the Dagbamba song riddles performances.

There is also at least an element that is carried from a response of the preceding line into the antecedent of the next line. That is, an element (if the response has one element) or the second element in every response is automatically the second element of the next antecedent and the second element of the song riddle antecedent becomes the first element of that same riddle's response. This creates a pattern in both the song riddle antecedents and their responses and also thus gives clues to the riddle performers as to which element follows and precedes the riddle elements in both the antecedents and the responses of the Dagbamba song riddle. For instance, tuya 'beans' in the first response is the second element of the next riddle antecedent after the first element $B J$ 'what' and for it being the second element of the antecedent, it occupies the first slot of the response to that riddle antecedent. Again, Bandi 'fetters' being the second element in the second response/line automatically becomes the second element in the next antecedent/line and that qualifies it to be the first element in the response of that antecedent. This is a phenomena that runs through all the Dagbamba song riddles. The performer in this case makes use of repetition as the basic ingredient to the use of a form of the last detail in one line of the piece becoming the first detail in the next line where the response contains a borrowed element (last element of the antecedent) from the antecedent making the borrowed element becoming the first detail in the response. Literary, this phenomena is termed as pilling. The interest of the riddler is on the additional detail which moves the riddle forward towards the riddling climax where the respondent will end the riddle with a proverb. The second element in the antecedent and first element or a phrase of the response often connects the antecedent to the response, except for the first response which has only one element. Such a connection involves the first element in the response of the antecedent as a pivot and serving as an intermediate outcome for the first two (2) elements of the antecedent and also as onset for the response. The riddler employs 'epanalepsis' repetitive type in the song riddle among the Dagbamba, where the riddler repeats the same words at the end and the start of each antecedent and response in the entire riddle to make his/her idea clearer and also show the significance of these repeated words in the riddle.

The song riddle of the Dagbamba riddles further employs repetition of some of its words several times in the riddle so as to create a melodic and an enhanced rhythmic effects in the riddle and also for emphasis. These words also serve as the link between the idea in the antecedent and the ideas in the response. This can be seen in the following excerpt.

Excerpt 2.
A: Bo m-be a nolini? 'What is in your mouth?'
A: Bo tuya? 'What beans?'
A: Bo bandi? 'What fetters?'
A: Bo kulo? 'What kulo?'
A: Bo kpam? 'What oil?'
A: Bo dirigili? 'What dirigili?'
A: Bo sangali? "What problem?'
R: Tuya 'beans'
R: Tuya bandi 'beans fetters'
R: Bandi kulo 'kulo fetters'
$\mathrm{R}$ : Kulo kpam 'kulo oil'
$\mathrm{R}$ : Kpam dirigili 'faded oil'
$\mathrm{R}$ : Dirigili sangali 'faded problem'
R: Sangali suyuls 'patience problem' 


\author{
A: Bo suyuls? 'What patient?' \\ A: Bo ku n-kpe? 'What can't enter?' \\ A: Bo yemba? 'What yemba?' \\ A: Bo tari? 'What wall plaster?' \\ A: Bo bolo? 'What bolo?' \\ A: Bo wumsi? 'What wumsi?' \\ A: Bo chayila? 'What jingles?' \\ A: Bo fiiyo? 'What fiiyo?' \\ A: Bo goy? 'What crooked?' \\ A: Bo piti? 'What piti?'
}

\author{
R: Suyuls ku n-kpe 'patience can't enter' \\ $\mathrm{R}$ : Ku n-kpe yemba 'ycmba can't enter' \\ R: Yemba tari 'yemba wall plaster.' \\ R: Tari bolo 'slippery wall plaster' \\ $\mathrm{R}$ : Bolo wumsi 'nurtured slippery' \\ R: Wumsi chayila 'jingles nurtured' \\ $\mathrm{R}$ : Chayila fiiyo 'fiiyo jingles' \\ R: Fiiyo goy 'crooked fiiyo' \\ R: Goy piti 'tasteless crooked' \\ R: Piti zaa m-bala ka m bi nya sheli. So yi je so bora. Lit: 'It is all \\ about tasteless that I have not had anything. What someone rejects is \\ what another person accepts.'
}

The last elements in the responses happened to be the last details of the successive lines in this case, the antecedents, are the borrowed elements which also become the first details of the responses. Thus, the element that is seen as the last detail of the antecedents determines the first detail of the response and the last detail of the responses determines the element that serves as the last detail of the antecedents. One can therefore predict what element begins or ends the response or antecedent respectively. This is an account of the pilling device employed by the riddler to move forward the riddle towards its climax.

Repetitive device accounts for more than one time appearance of words in the riddle by the performer. At least with the exception of the interrogative $B$ o 'what', each word in the response is repeated thrice in both the antecedent and the response. Restating these words in the riddle is to make emphasis on the significance of these words and for a rhythm.

It is worth to note that, devices employed in the song riddles and other forms of oral literature are designed to achieve the sense of fullness and also impress the audience with depth and variety of wisdom of the performer. This might be what informed Atintono and Nsoh [3] to postulate that it may not be possible for a riddler to compose and perform a riddle without employing any literary device in its right dosage.

Again, the antecedents of the Dagbamba song riddle have a similar ending pattern, that is, they have their initial sounds/letters capitalized and punctuated at the end of the riddle antecedent with a question mark [?]. The responses are also not punctuated but have only their initial sounds/letters capitalized. This also gives the responses of the Dagbamba song riddles similar patterns. These, thus creates a balanced pattern in the antecedents and the responses of the song riddle performance among the Dagbamba.

There is again a pattern of the number of elements employed by the performer in a Dagbamba song riddle antecedents and responses. In the first antecedent, the performer employed 4 elements but used only an element as its response. The performer also employed the same ratio of elements in all the antecedents and responses of the Dagbamba song riddles with the exception of the middle antecedents and responses where the performer will either use 2 elements in the antecedent to 3 elements in the respective response or 3 elements to 3 elements in both the antecedent and the respective response. Thus, the ratio of the elements used in all the antecedents and their respective responses is 2:2 with the exception of the 2 riddle antecedents and their respective responses in the middle where the ratio is $2: 3$ and 3:3. In effect, the Dagbamba song riddle performer employed four elements in the first antecedent which has an element as its response. This, thus does not make a balance ratio. The performer again introduced a non-balance ratio in the middle and at the end of the song riddle. This, thus creates a peculiar structure in all the Dagbamba song riddles making all of them performed in a similar style of element pattern.

Further, apart from the first and the last riddle antecedents and their responses that do not have equal number of elements in both the riddle antecedent and the response, the Dagbamba song riddles have a balanced pattern of two or three elements except the first antecedent that has 4 elements and its corresponding response also has just an element and the last antecedent which has 2 elements with a corresponding 16 elements in its response (a proverb). Again, the riddle antecedent/line 8 has 2 elements and its corresponding response has 3 elements. The rest of the riddle antecedents have the same number of elements with their responses, that is, 2 elements each.

\subsection{Syllabic Pattern and Didactics}

Syllabic pattern is one of the styles employed by the Dagbamba song riddle performer. Another manifestation of a tendency towards a uniform syllabic model is the avoidance of closed syllables at the end of the line. The number of syllables in the line from the beginning to the last is stable. There are most of the times no syllable correspondence between the antecedent and the response but short and open syllables are the most prominent used syllables by the performers in the Dagbamba song riddle. One can find a closed syllable only when a word is monosyllabic and also nasal consonant ending the word. For instance, kpam 'oil' in the fourth response and in the fifth antecedent and its response and lam 'taste' in the twelfth response and the thirteenth antecedent and its response are the only closed monosyllabic words that have their codas ending with the bilabial nasal consonant $/ \mathrm{m} /$. But in disyllabic words such as bandi 'fetters' in the response of the second antecedent and 
also in the third antecedent and its response have the nasal consonant $/ \mathrm{n} /$ as the coda in the first syllable $/ \mathrm{ban} /$ of the word. Again, sangara 'problem' in the response of the sixth antecedent and also in the eighth antecedent and its response have the nasal consonant $/ \mathrm{n} /$ as the coda in the first syllable /san/ of the word sangara 'problem'. Suyulo 'patient' in the seventh response and the eighth antecedent and its response and payasara 'ladies' also in the response of the tenth antecedent and the eleventh antecedent and its response have $/ \gamma /$ as the coda of the first syllable /suy/ and /pay/ respectively. Also, the coda of the first syllable /yem/ of $y \varepsilon m b a$ 'meaningless' in the response of the ninth antecedent and the tenth antecedent and its response is $/ \mathrm{m} /$. Finally the word wumsi 'nurse (s)' in the response of the fifteenth antecedent and the sixteenth antecedent and its response also have the nasal consonant $/ \mathrm{m} /$ as the coda in the first syllable /wum/ of the word. There is also a prominent syllabic pattern in both the riddle antecedents and their corresponding responses. Most of the riddle antecedents have three syllabic pattern with the first element of the antecedents having monosyllabic pattern throughout the riddle antecedents while the second elements having disyllabic (two or more syllables) pattern. For instance, the second, third, fourth, sixth, eighth, tenth, fourteenth, fifteenth, sixteenth, eighteenth, twentieth antecedents all have three syllabic pattern whilst the fifth, twelfth, thirteenth and nineteenth antecedents also have two syllabic pattern. Again, the seventh, ninth and eleventh antecedents have four syllabic pattern. On the other hand, it is only the first response that has two syllables pattern. The fourth, fifth, twelfth, thirteenth, nineteenth and twentieth responses have three syllables pattern while second, third, eleventh, fourteenth, fifteenth, sixteenth and seventeenth responses have a similar syllabic pattern of four. Also, the sixth, seventh, eighth, ninth and tenth responses have the same syllabic pattern of five. Therefore, the Dagbamba song riddle antecedents have a syllabic pattern of $6,3,3,3,2,3,4$, $3,4,3,4,2,2,3,3,3,3,3,2$ and 3 while the responses have a syllabic pattern of 2, 4, 4, 3, 3, 5, 5, 5, 5, 5, 4, 3, 3, 4, 4, 4, 4, 3 and 3 . With this, the performer employs different patterns for the song riddle antecedents and their corresponding responses but repeats some of the patterns employed in both the antecedents and the responses. Thus, apart from the first antecedent, the rest are at least repeated three times in both the antecedents and the responses of the song riddle. Interestingly, the syllables patterns in the above song riddle have syntagmatic pattern often constructed with paradigms except antecedents/lines 4,11 and 18. It is also worth noting that, the last response is not considered part of the syllabic pattern analyses since it is a proverb that contains

Excerpt 3.
A: Bo m-be a nolini? 'What is in your mouth?'
A: Bo tuya? 'What beans?'
A: Bo bandi? 'What fetters?'
A: Bo kulo? 'What kulo?'
A: Bo kpam? 'What oil?'
A: Bo dirigili? 'What faded?'

many words.

All these are stylistics qualities employed by the Dagbamba song riddle performer unwittingly for effective performance of the Dagbamba song riddle. This, therefore, conforms to Agyekum's [2] assertion that, stylistics qualities generally, are employed to enhance the oral artistic work and for the audience to enjoy the performance.

Sanortey [18] concedes that songs are considered as a very important form of communication. The message of songs will enable an individual to come to terms why certain things are done the way they are done among certain group of people.

The message the Dagbamba song riddle literally carries is that, there is something that is hidden somewhere, when one is introduced to it, they will be fettered to it. This thing looks like an oil that has lost its original colour. This oil is accompanied with problems and with patience the problems get into you. When tested, one is plastered and stitched to this oil though tasteless and slippery and from a bent thing, nursed in the testicles and liked by everyone. Rejecting it will mean losing greatly and paving a way for someone else to enjoy what you either lost or feel it is not worth enjoying and feel proud of it. Accordingly, it is not only the things that we taste through the mouth that we feel or enjoy the taste but there are other places within human body that we also feel or enjoy the taste of something. Apparently when we critically examine this riddle, the riddler is trying to juxtapose the menace and importance of sex through the figurative use of the words because premarital sex was frowned at and sometimes a punishable offence among the Dagbamba. To the married couples, sex is something that is enjoyable though normally not done through the mouth that normally senses sweetness. Once one practices sex they become addicted to sex because one's instincts will drag one to it, especially, when the sperm turns to fertilize and every 'normal' human being likes sex. One may also not want to stop it for the fear of regret for someone else to grasp, enjoy and boast with it. The performer also uses these words as a means of employing consistent rhetorical indirection to veil the sexual menace due to the protean nature of the language. Though the attention of the performer is on the married couples, the performer on the other hand could also perform the song riddle to send a word of caution to the unmarried since pre-marital sex has its own effects. When one tastes sex and becomes fettered and plastered to it and cannot again stop having it, the consequences of becoming fettered and plastered to sex could be teenage parent especially when it results to teenage pregnancy and it could also affect the individual's growth.
R: Tuya 'beans.'
R: Tuya bandi 'beans fetters.'
R: Bandi kulo 'kulo fetters'
R: Kulo kpam 'kulo oil'
R: Kpam dirigili 'faded oil'
R: Dirigili sangali 'faded problem' 


\author{
A: Bo sangali? "What problem?' \\ A: Bo suyulo? 'What patient?' \\ A: Bo ku n-kpe? 'What can't enter?' \\ A: Bo yemba? 'What yemba?' \\ A: Bo tari? 'What wall plaster?' \\ A: Bo bolo? 'What bolo?' \\ A: Bo wumsi? 'What wumsi?' \\ A: Bo chayila? 'What jingles?' \\ A: Bo fiiyo? 'What fiiyo?' \\ A: Bo goy? 'What crooked?' \\ A: Bo piti? 'What piti?'
}

In the above song riddle examples, words such as kulo, yemba, and fiiyo are ideophones (meaningless elements). According to Abubakari [1: 44-45] and Dingemanse [6: 655], ideophones create specific mental or sensory imagery as well as echo specific sound movements in a way that no other class of words does and that they modify either nouns or verbs but cannot stand on their own. Ideophones are manmade sounds and according to Manyah and Marfo [14], sounds and voices are two side of the same coin. In the Dagbamba song riddles, these ideophones are employed by the performer to mentally create sexual imagery, for suspense, and to develop fluency skills in children when they continuously perform riddles. The performer also introduces semantic ambiguity by symbolically employing in the song riddles words like diti/dirigili, to mean something that loses its original colour. Bolo also to mean something that looks slippery, in the song riddle context, bolo is taken to be sperms. Chayila 'jingles' which has some little resemblance with the testicles, in the song riddle context meant testicles symbolically. Again, fiiyo is also taken to mean something that is liked by everyone or the most liked among everything or something that has a very close resemblance with something. Because penis is not looking straight whether erected or not, goy 'crooked' is also taken to symbolically mean penis. Finally, piti 'tasteless' to mean something that can't be orally tasted or something tasteless.

Therefore, because the Dagbamba culture frowns at profanity - plainly referring to certain items by their real names in public for the sake of being seen to be spoilt, the song riddle performer euphemized kulo and goy for penis, diti/dirigili, piti and bolo also to mean sperms and chayila to symbolically represent testicles.

Harries [10] observes that the Makua song riddles are connected with initiation rituals. Though, not established, the Dagbamba song riddles could have also been connected with initiation rituals (especially females) since the Makua and the Dagbamba song riddles have similar didactics and include sexual references or allusions. But the Dagbamba song riddles performance are not forbidden to non-initiates, therefore anybody can perform or learn the song riddles.

Notably, the Dagbamba song riddles do have some few elements and the proverbs as the differences between them. In other words, the performer of the Dagbamba song riddles
R: Sangali suyulo 'patience problem.'

R: Suyulo ku n-kpe 'patience can't enter.'

R: Ku n-kpe yemba 'ycmba can't enter.'

R: Ycmba tari 'ycmba wall plaster.'

R: Tari bolo 'slippery wall plaster.'

$\mathrm{R}$ : Bolo wumsi 'nurtured slippery'

R: Wumsi chayila 'jingles nurtured.'

$\mathrm{R}$ : Chayila fiiyo 'fiiyo jingles'

R: Fiiyo goy 'crooked fiiyo'

R: Goy piti 'tasteless crooked.'

R: Piti zaa m-bala ka m bi nya sheli. So yi je so bora. Lit: 'It is all about tasteless that I have not had anything. What someone rejects is what another person accepts.'

employs some few different words and varied proverbs in all the song riddles to differentiate them from one another. Therefore, the Dagbamba song riddles have same words usage of about $90-95 \%$ in them.

The relationship the Dagbamba Song riddle has with the Dagbamba society

Gee [9], posits a statement of its major theme (p. 143):

...in our everyday lives and in much traditional psychology, what we think of as 'mental' is in fact, 'social'. Meaning and memory, believing and knowing, are social practices that vary as they are embedded with different Discourses within a society. Each Discourse apprentices its members and 'disciplines' them so that their mental networks of associations and their folk theories converge towards a 'norm' reflected in the social practices of the Discourse. These 'ideal' norms, which are rarely directly statable, but only discoverable by close ethnographic study, are what constitute meaning, memory, believing, knowing, and so forth, from the perspective of each Discourse.

Just like other forms of oral literature, the Dagbamba song riddles reflect the Dagbamba culture which thus requires knowledge of the Dagbamba culture for one to guess the answer of any Dagbamba song riddle. Apart from the song riddles serving as a source of entertainment, they show how fast or intelligent an individual is, bring unity among the people, influence someone's action and teach rules of social conduct. This is justified in Awedoba [4], when he says riddles have significant latent or overt social roles. The Dagbamba song riddle also has a number of relationships with the Dagbamba as a people. Some of these relationships are from the interpretations of these riddles. The Dagbamba riddle has much more to do with real life situations than mere mentioning of objects as referents and responses.

In the past, among the Dagbamba, it was a taboo for couples to divorce. The Dagbamba song riddle, as a kind of riddle was performed to highlight the need for couples to stay together no matter the circumstances. In the song riddle, the performer tries to use certain words to depict how couples should live together. The use of bandi and tari 'fetters and wall plaster' in the riddle implies that, when two individuals agree to become couples, they are fettered and plastered to each other. They are supposed to do everything in common and also see each other as one since they have agreed to live 
together under one roof. With this, no matter the circumstances, even when situations become diti 'faded/hard', an individual needs not try to break the fetters that binds them together or remove the mortar that plastered them together since breaking or removal of these fetters and plasters could lead to destruction. When these fetters and plasters are removed, the bond that created the ties between these two families that agreed to marry their children out to each other will definitely break, thereby creating problems like enmity between these families which could affect their generation and unborn generations. With this, some families would no longer accept a family member from the other family and no family member from either family would be allowed to marry or have any dealings with the other family. This could, sometimes, lead to pouring of curses on either family members depending on the degree of the damages caused by the divorce. This, sometimes, leads to the performance of libation, especially, when the aggrieved families wish to amend their ways or when the generation that poured the curses on the either families are no more but the families involved are willing to amend. To avoid this, the performer tries to introduce suyulo 'patience' in the riddle to tell couples to always have patience in dealing with each other and that with patience anything is possible. Again, the performer also tries to say in the riddle that, no matter how bad something is, there is always something good about it too. So if one lets go the marriage, someone else will go for what you could not keep and live with it, for there is always something they will like about the person you have left and you will lose. This is depicted in the final response of the riddle which is a proverb that says that, Daadali bincherili ka so yun pihi mali gohira 'It is the market day's rag that someone gets and brags with it.' Or so yi je so bora 'if you don't like something someone else likes it.'

Auden cited in Fenton [7] posits that the primary function of poetry is to make us become aware of ourselves and the world around us. Auden's assertion might be the underlying factor for the purpose of which the Dagbamba song riddle was enacted and performed so as to make Dagbamba aware of themselves in terms of divorce/sex and its menace and how this could be managed.

\section{Conclusion}

Clearly, these findings suggest that the richness of syntax which linguistics finds in every normal child may be accompanied by the richness of narrative organization. The degree to which this is so cannot be assumed in advance. One has to know something of the state of the art of narrative in the community in question, and many communities have been buffeted in ways that erode traditional narrative art.

Modern society does debase local tradition and creativity but does not succeed in eradicating it. Inasmuch as the generative principles of language and narrative are universal, and the need to 'traditionalize' experience intrinsic to meaningful human life, we can expect some degree of preschool, and out-of-school, oral narrative experience to be as lasting as humanity itself. Its richness will wax and wane with forces over which schools have no control, but schools will be more effective if they realize its presence and take it into account. Insofar as schools see themselves as outposts of great tradition, missionaries to their districts, the indigenous oral patterns and potentialities may be factors to be taken into account in transmitting another message. Insofar as schools can see their mission as the etymologically appropriate one of educating in the sense of drawing out, discovery of this kind of patterning can be a source of encouragement and stimulation.

\section{References}

[1] Abubakari, H. (2017). Ideophones in Kusaal. Journal of West African Languages, vol. 44.1, 42-57.

[2] Agyekum, k. (2013). Introduction to Linguistics. LegonGhana: Adwinsa Publications (GH) Ltd.

[3] Atintono, A. S. and Nsoh, A. E. (2001). Asserting the Literariness of "Riddles": The Case of Solengirisi of Farefare in Northern Ghana. In In Cahiers du CERLESHS. Actes $d u$ colloque inter-universitaire sur la coexistence des langues en Afrique de I' Ouest. Ouagadougou du 26 au 28 septembre, 192-206.

[4] Awedoba, A. K. (2000). Social Roles of Riddles with Reference to Kasena Society. African e-Journals Project, 16 (2), 35-51.

[5] Bodomo, A. (1996). On Language and Development in Africa: The Case of Ghana. Nordic Journal of African Studies, 5 (2), 31-35.

[6] Dingemanse, M. (2012). Advances in the Cross-Linguistic Study of Ideophones. Language and Linguistics Compass, 6 (10), 654-672.

[7] Fenton, James (2003). The Strength of Poetry. Oxford University Press.

[8] Finnegan, R. (2012). Oral Literature in Africa. Cambridge: OpenBook Publishers. http://doi.org/10.2307/216450

[9] Gee, J. P. (1992). The Social Mind: Language, Ideology and Social Practice, Series in Language and Ideology, Macedo, D. (Ed.) New York: Bergin and Garvey.

[10] Harries, D. (1942). Some Riddles of the Makua People. African Studies. Vol: 1.

[11] Hymes, D. (1996) Ethnography, linguistics, narrative inequality: Toward an understanding of voice. London: Taylor \& Francis.

[12] Jakobson, R. (1960). 'Concluding Statement: Linguistics and Poetics', in SEBEOK, T. A. (Ed.) Style and Language, Cambridge, MA: MIT Press, pp. 350-77.

[13] Manuel, E. A. (1962). Bagobo Riddles. Quezon City: University of the Philippines.

[14] Manyah, K. A. \& Marfo, C. O. (2016). Dominant Voices and Sounds of Akan Proverbs and Riddles. Social Socience and Humanities Journal, 212-221. 
[15] Maureen, W-L. (2004). Caribbean Verbal Art in African Folklore an Encyclopedia, Philip, M. P. and Yankah, K. (Ed). New York: Routledge.

[16] Nsoh, E. A., Fusheini, A - R. and Ababila, J. A. (2010). Aspects of Oral literature in Ghana: with illustrations from sellected languages. Saarbrucken, Deutscland: LAMBERT Academic Publishing.
[17] Okpewho, I. (1992). African oral literature: Bacgground, character, and continuity. Bloomington and Idianapolis: University Indiana Press.

[18] Sanortey, T. (2012). The aesthestics of Kontomboor songs. Mphil Thesis: University of Education Winneba. 